\title{
Hispanoamérica y Brasil: Encuentros, desencuentros, vacíos*
}

\begin{abstract}
Ana Pizarro
Universidad de Santiago de Chile

E-mail: apizarro@usach.cl

\section{Resumen}

A partir de la metáfora de la heteronimia elaborada por Fernando Pessoa, se aborda el problema de la articulación común de un espacio latinoamericano en función de la multiplicidad de sus áreas culturales, considerando en particular las relaciones entre H ispanoamérica y el Brasil. D esdeuna mirada estructural, se advierte que en ambos bloques existen núcleos de productividad simbólica quese articulan al incorporar lastensiones propias de nuestra cultura en su condicionamiento periférico. Así, la construcción de un espacio alternativo emergente en la colonia, la estética de la homogeneidad nacional y la tensión regional-cosmopolita de la modernización son dispositivos que otorgan un sentido de "unidad" a estos bloques, si bien evidenciando asimismo sus divergencias. H oy, además de explorar el efecto quesobreestas vinculacionestienela introducción dela escena mediática, seplantea el interés de aproximarse, manteniendo una mirada de conjunto, a las relaciones históricas concretas establecidas por viajeros e intelectuales, como es el caso de Gabriela $\mathrm{M}$ istral. Se concluye postulando la pertinencia de examinar los distintos espacios de contacto entre estos bloques, tales como las delimitaciones conceptuales, los ejes externos, los viajes y las fronteras. D entro de ellos, la Amazonía se perfila como una región que urge conocer en la perspectiva de reivindicar su pertenencia.
\end{abstract}

Palabrasclaves: Cultura latinoamericana, áreas culturales, Latinoamérica, Brasil, Amazonía.

\section{Abstract}

In this contribution, the shared articulation of a Latin-American space from the multiplicity of its cultural areas is approached through Fernando Pessoa's metaphor of heteronomy. Relations between $\mathrm{H}$ ispanic-America and Brazil are especially taken into account. From a structural outlook, both cultural blocks have productive symbolic nucleus which articulatethemselves by integrating tensions of our culturein itsperipheral conditionings. Thus, the construction of an emergent alternative spaceduring the colonial period, as well

* Este texto fue lédo en la apertura de la sección sobre "Relaciones H ispanoamérica y Brasil", $14^{\circ}$ Congreso de la Asociación Alemana de $\mathrm{H}$ ispanistas. Ratisbona: Universidad de Ratisbona, 6-9 de marzo 2003. 
as the national homogeneity esthetics and the regional-cosmopolitan tensions of modernization give them a sense of "unity" - even if they also show their divergences. Today, besides exploring the effect of media on these links, it is interesting to approach - maintaining an overall viewpoint- concrete historical relations established by single travelers and intellectuals such as $\mathrm{G}$ abriela $\mathrm{M}$ istral. The conclusion is that it ispertinent to examine different spaces of contact between Brazil and H ispanic-America, such as conceptual de limitations, external axis, travels and frontiers. Among these, the Amazonian region is profiled as one which is urgent to become acquainted with in order to vindicate its belonging to Latin America.

Keywords: Latin American culture, Cultural areas, Latin America, Brazil, Amazonian region.

Recibido: 14-07-2003. Aceptado: 24-09-2003.

- N EL INTENTO de entender el complejo juego de aproximaciones y desvíos internos que anima la vida de nuestra cultura latinoamericana, entendida siempre como desarrollo propio de formaciones que emergen y adquieren su perfil en condiciones de periferia, quiero proponer una metáfora. Es la metáfora de la heteronimia. Como sabemos, su origen está en Fernando Pessoa. El poeta escribe como tal, pero también se desdobla en Ricardo Reis y otros heterónimos de escritura, personal idad e historia diferentes. Es decir, Fernando Pessoa es él y es cada uno de los otros, es él y todos los demás y al mismo tiempo cada uno de ellos constituyeuna personalidad, un discurso individual y diferente del otro. Pero son al mismo tiempo Fernando Pessoa. Tomo conscientemente esta configuración deescritura y escrituras de un poeta del mundo metropolitano, aunque marginal en un país periférico a la corriente central europea. La tomo y la transformo en un modo de comprensión del funcionamiento de los discursos culturales del continente. La llevo de la complejidad de lo individual a la complejidad de lo colectivo. Porque al pensar en la organización de nuestras culturas, necesitamos identificar modos de entender las convergencias, las divergencias, los desarrollos, los paralelos, los vacíos. La complejidad tiene que ver con la multiplicidad y también con la articulación de un espacio cultural común. Allí el término "continente", que usamos a menudo, resulta estrecho y excluyente, con la incorporación del Caribe en sus distintas vertientes, así como con la de la cultura latina en los Estados U nidos. Es por eso que necesitamos entenderlo en términos también metonímicos.

Al pensarlo así, la heteronimia latinoamericana hace evidente, pues, que el discurso de esta cultura prolifera en el espesor de sus varias áreas. Cada una de ellas es América Latina, pero al mismo tiempo no lo esaisladamente. La mesoame ricana y andina se prolonga de norte a sur por la costa oeste y expresa los distin- 
tos modos y momentos de lo que se ha llamado, como sabemos, la transculturación hispano-indígena, asentada en las sociedades de origen más complejas y configuradas en términos de estado. Es por ello, tal vez, la que ha tenido mayor visibilidad en las perspectivas críticas e historiográficas. Pero al mismo tiempo ha condicionado la existencia de una mirada sobre América Latina marcada por un "andinocentrismo", que ha hecho soslayar a otros sectores de expresión cultural no menos importante. Así, los modos expresi vos de lo que Rama llamó el área sudatlántica, marcada por los efectos de la inmigración europea de fines del siglo XIX y comienzos del XX como correlato de la crisis económica y su efecto en las regiones más pobres de ese continente, aparecen como un "desvío" extranjerizante-América Latina se presume hispana eindígena- y por lo tanto un cuerpo exógeno. Como hemos señalado alguna vez, esta área sin embargo expresa uno de los modos más peculiares: cómo esta cultura - de vanguardia, dijo Rama- se apropia de la europea de origen inmediato a través de la inmigración y, por no formar parte a cabalidad de su tradición, es capaz de transgredirla, transformarla, proyectarla.

El área caribeña entró tardíamente a formar parte de las preocupaciones del latinoamericanista. Yo diría que aún no se identifican con claridad, en sus articulaciones internas, sus subáreas no hispanas; lo que hace que culturas ligadas a lenguas y tradiciones metropolitanas diferentes experimenten esa ligazón submarina de la que han hablado sus intelectuales. Esa relación fundamental en historia y futuro que fue lo que determinó la economía de plantación, las sociedades a que ella dio lugar, sus modos de imaginar el mundo recuperando una historia fragmentaria y absorbiendo la experiencia del presente de manera no menos fractal. El interés por el estudio del área caribeña tuvo su impulso al rededor de los años sesenta del siglo XX, en que las migraciones hacia los Estados Unidos por razones económicas, políticas y sociales comenzaron a darse con mayor vigor. Estas migraciones, que habían sido precedidas por las delos mexicanos y luego los centroamericanos por razones de inestabilidad política y económica, también irían a ver la emergencia de una nueva área cultural en el ámbito latinoamericano: la de los "latinos", un país de treinta millones de habitantes dentro del país mayor, que vive en distintos grados una situación peculiar. Es la de culturas de "entrelugar", campos que se construyen en la negociación, en el desarraigo, en el desasosiego de un espacio no territorializado en que dos culturas se penetran, se dislocan, se repelen, se aproximan en medio de un imaginario de culpabilidades, esperanzas, nostalgias, negaciones, proyectos. El espacio de una muerte cultural, el espacio de un nacimiento, el de una transformación, en fin, con todos los dolores y alegrías que ello implica.

El Brasil constituye como área el gran "espacio cultural no identificado" desde la América hispana. No hablaré del desconocimiento entre ambos secto- 
res porque ya es un lugar común aunque aún no estamos conscientes de ello. EI problema más bien es cómo reconocer nuestras diferencias, nuestras aproximaciones, nuestros paral elismos, los desvíos. Se trata, como sabemos, de un espacio que ocupa la mitad del continente, que está organizado en subáreas a veces muy diferenciadas - tiene su propia heteronimia, como la tienen internamente todas las demás áreas- y en cuyo interior se asienta gran parte de otra de las mayores, en superficie, en complejidad, en multiplicidad de discursos: la Amazonía. Sobre ella, como espacio de confluencia entre la América hispana y la lusitana, como ámbito cultural de perfil complejo, múltiple en discursos y con rasgos específicos de conformación cultural, nos gustaría extendernos un poco al final de esta exposición. Es lo que actualmente estamos estudiando.

Las relaciones culturales entre las áreas hispana y lusitana han sido, como sabemos, bastante soslayadas. C reo quees necesario entender su incomprensión en el marco no sólo de la historia americana, sino observar que ella se remonta a las divergencias y rivalidades entre las metrópolis de origen. Siendo vecinas en Europa y situándose culturalmente ambas en un escenario histórico más cercano a la Edad M edia que al Renacimiento, tuvieron en cambio profundas diferencias que hicieron tal vez que en el obstáculo de una lengua muy cercana se proyectaran dos perspectivas del mundo que desde el primer momento no permitieron la aproximación. El que Portugal tuviese ya una experiencia vasta de dominio del mar que lo había llevado a lo largo de las costas africanas hasta el extremo sur, y dándole vuelta al Cabo de Buena Esperanza hasta el Asia, hacía emerger desde ya experiencias divergentes. Al comparar ambas conquistas, J osé Veríssimo anotaba:

No hay en la conquista portuguesa de América nada comparable a la española de M éxico, del Perú o de C hile. Las propias luchas civiles aquí no han tenido jamás -y por suerte- la repetición, la duración, la crueldad de luchas semejantes en las colonias españolas, antes 0 después de la independenciaª

En la perspectiva de los portugueses ya existía el conocimiento dela alteridad, ellos habían convivido con otras lenguas y culturas, otras religiones, incluso el continente recién descubierto no tenía para el portugués la importancia de los dominios asiáticos y por lo tanto su relación con él fue más laxa que en el caso del español. Incorporaba la nueva realidad con un catolicismo más abierto que España, el mestizaje con menor reticencia al contacto. Si debajo de la línea del Ecuador todo estaba permitido, como rezaba el proverbio portugués, la Tierra deSanta Cruz transformó pronto su denominación y el color extraído del palo

${ }^{1}$ Citado por Schwartz (1993). 
Brasil demonizó su perfil. Las visitaciones de la I nquisición no hacían entonces sino constatar lo esperable. Y aunque ambos conquistadores no llegaron con las manos vacías sino con una mochila bien cargada, que contenía imaginarios prove nientes de diversos momentos históricos desde la antigüedad greco-latina, por estas mismas razones, entre otras, estos imaginarios tenían muchas veces diferentes sentidos.

Es así como, y a partir de esta situación, la emergencia de nuestras dos culturas en los términos que lo hicieron, los de culturas construidas con un estatus colonial, en un marco de periferia, hizo que su evolución tenga hasta hoy la complejidad de relaciones de convergencia y divergencia, reconocimiento y extrañeza, así como desarrollos paralelos, todos ellos en el espacio hegemónico de culturas metropolitanas que política o simbólicamente se constituyen en polos de referencia para el proceso de apropiación creativa: España, Portugal, Francia, en el siglo XX los Estados U nidos.

Esto hace entonces que podamos observar centros de producción simbólica comunes, quearticulan procesos próximos; quepodamos constatar operaciones culturales, dispositivos constructores de comunidad, en la dirección de un territorio de imaginarios de estructuras similares.

El primer dispositivo simbólico tiene que ver con la construcción de un ámbito discursivo que se perfila a partir de la emergencia de una entidad alternativa a la cultura europea. América apuntaba a nominar un espacio que si algún rasgo definitorio tenía era el de ser un territorio de superposiciones y cruces, de intersecciones lingüísticas, un espacio en vertiginoso movimiento de construcción cultural. Imposible de ser aprehendido en conjunto por la reflexión, constituyó sólo el lugar del mito, y de él se hizo cartografía, con él se construyeron relatos, cartas e informes. El mundo indígena se afincó en su imaginario y a partir de él desestimó o inició, como en el caso mapuche, la rebelión.

El primer enfrentamiento fue pues el ámbito inicial del cruce de los imaginarios. No había vacíos, ninguna de las dos culturas era inocente. Ambas estaban cargadas de historia y el traumatismo de unos impulsaba la perplejidad y el desenfreno de los otros, iniciando así una dialéctica de producción de sentidos en la que la historia aportaría la complejidad.

Los textos, como el arte, contemporáneos a la conquista ponen en juego las fracturas, los desplazamientos, las superposiciones, la pluralidad de dimensiones y velocidades con que la escena colectiva de la creatividad inicia la violenta transformación. Es la "colonización del imaginario" como lo ha llamado con belleza Serge Gruzinski. Las fantasías impulsan las voluntades a terrenos de locura y los "hombres al ucinados" de que habla Cecilia M eireles se internan en la selva buscando las ciudades del oro y las fuentes de la juventud eterna. 
Así, los textos de los inicios convocan la escena de la intersección, exploran la intensidad, construyen la gramática a que dan origen sus pulsiones, constituyéndose en el espacio de dos monólogos que apenas al tocarse en diálogo se superponen, se repelen, se solapan, se transgreden. Allí los desplazamientos y las imposiciones comienzan a dar paso, en el sujeto colonial colonizado, a una pre sencia otra, y en el sujeto colonizador, a un espacio de discurso subvertido en su constitución genérica: en sus aprehensiones de la realidad, en su argumentación, en su sintaxis discursiva. D an paso a un espacio discursivo diferente y germinal, a una subjetividad alternativa. El perfilamiento de este territorio emergente de la lengua, la literatura y la cultura es la primera operación que observamos.

Si en Juan Ruiz de Alarcón y en Sor Juana ya hay un paso decisivo, los textos de los historiadores mestizos y los de los jesuitas en exilio dan profundidad y amplitud a la transgresión. El "saudadismo" de losúltimos propicia un discurso de americanidad que encuentra su gesto en la afirmación de lo natural. En el ámbito luso-americano hay, en esta misma dirección, un famoso poema de exilio un poco posterior, 1843, de Gonçal ves $D$ ias, que dice con deliciosa ingenuidad:

\section{$M$ inha terra tem palmeiras \\ O nde canta o Sabiá \\ As aves que aquí gorgeiam \\ $\mathrm{N}$ ao gorgeiam como la.}

$\mathrm{H}$ ay en todos ellos una necesidad de nombrar, la afirmación de un espacio. M ás allá de la demarcación militar de un territorio geográfico, el advenimiento de las repúblicas va a instaurar un tiempo. La memoria compartida sobrela cual van a asentarse las comunidades que están diseñando las burguesías criollas, el tiempo de una tradición con sus héroes, sus panteones, como sabemos, y, sobre todo, el establecimiento de las lenguas oficiales del continente: el español y el portugués para cada una de las grandes áreas. Para establecer este pacto del imaginario se instalan, pues, las banderas, los himnos, los distintivos de afirmación de un territorio y deuna historia. La lengua y la literatura, como el retratismo en la pintura de la época invocarán la precaria solidez de las naciones en ciernes, asumirán el designio de los proyectos nacionales. Encontrarán el apoyo necesario en los pintores viajeros - Rugendas, D ebret- que perfilan los espacios temáticos con la mirada de afuera. Proyectos homogeneizadores desde las el ites criollas de lenguas, razas y culturas en donde lo nacional entrará en juego con el proyecto político continental.

Estamos en el momento del segundo dispositivo simbólico a que queremos aludir, el de la constitución en los imaginarios del proyecto nacional. 
Las discusiones sobre la lengua, tanto en $\mathrm{H}$ ispanoamérica como en Brasil, apuntan a la apropiación por parte del continente de las lenguas metropolitanas. La gramática, la ortografía junto a los códigos legislativos entregan, en Andrés Bello, la medida de la importancia. Son instauradores de la nación al mismo tiempo que disciplinadores de sociedades multilingües y pluriétnicas que es ne cesario capturar en el patrón común.

El espacio simbólico de la novela tiene que ver con esa función hegemónica delas letras durante el XIX, pero en su tensión con propuestas desconstructoras que ponen en evidencia la otredad estructural de nuestras formaciones.

El tercer dispositivo simbólico que construye la articulación entre las áreas hispana y lusitana pertenece más bien al siglo XX y tiene que ver con las propuestas que interrogan al espacio de productividad de sentidos que incorpora la modernización.

D esdeel siglo XIX se había ido perfilando una línea de escritura regional ista que toma cuerpo con distinto signo a comienzos del XX. Es el momento de los indigenismos, los afroantillanismos, los criollismos, la novela llamada "de la tierra", los regional ismos brasileños. Es la mirada al mundo rural desde la urbanización naciente, la tematización de lo nacional en tipos humanos, medio geográfico, en la explotación económica, en la reivindicación que denuncia el subdesarrollo, mirada que no pocas veces se desliza hacia la folklorización. El comienzo de siglo significa al mismo tiempo - con la urbanización en marcha, con la transición de modelo económico de velocidades diferentes en distintos sectores del continente, los procesos inmigratorios que hacen explosivo el crecimiento de al gunas zonas, como Buenos Aires y Sao Paulo, con la revolución tecnológica de esos años en los países centrales-una modernización violenta queperfila a la cultura en un diseño de juego entre espacios tradicionales y polos demodernización.

Así se enfrentan regionalismos y vanguardias, dos formas de aproximación cognoscitiva a la realidad en un momento de transformación social vertiginosa en donde ese dualismo rural-urbano, que expresa dos temporalidades diferentes, se va estructurando, desestructurando y reestructurando en un proceso de complejización creciente.

Es a través de las ciudades por donde entra el proceso modernizador tecnológico. Las vanguardias en América Latina, como hemos apuntado alguna vez, se desplazan entre el signo político de la lucha antidictatorial, la reconsideración étnico-antropológica y la elaboración de un discurso asentado en el proceso modernizador. Es el caso de O liverio Girondo en la Argentina o de Vicente H uidobro en Chile. EI caso de 0 swald y $M$ ario de Andrade en Brasil. Se trata de escrituras que incorporan el cambio de horizonte vital de la primera revolución tecnológica del siglo. La electricidad, el teléfono, el cinematógrafo, el salto en 
las comunicaciones en general, implican una diferencia substancial en la consideración del tiempo y el espacio que el territorio periférico absorbe desigual y segmentadamente.

Este ingreso de América Latina a la modernidad tecnológica, que es la contemporaneidad internacional -en lo cultural-literario, el momento en que se ponen a la hora los relojes transatlánticos, como dijera Angel Rama- , interroga al discurso estético en sus formas y sus modos expresivos. La discusión entre Anita M alfatti y M onteiro Lobato en Brasil, la siempre escandalosa eclosión de los grupos de vanguardia en los distintos países y sus polémicas, ponen en evidencia el vigor de la tensión entre regionalismo y cosmopolitismo. Preguntarse por las formas que más cabal mente expresan al continente es al mismo tiempo hacer una reflexión sobre el futuro. En este sentido las operaciones culturales del comienzo de siglo en ambasáreas deA mérica Latina se perfilan en la tensión entre las respuestas regional y la cosmopolita, en la clásica observación deAntonio Cándido, o en términos mayormente confrontacionales, entre la nativista y la modernólatra.

La tensión y sus consecuentes operaciones culturales atraviesan, pues, con formulaciones diferentes gran parte del siglo y ya en la década del 30 y 40 empieza a encontrar respuestas más integradoras, primeramente en la plástica, con Lam, Tamayo o M atta. El antecedente es Kalho, Tarsila do Amaral, Amelia Peláez. Luego crecientemente en la literatura.

En esta tensión se diseña el tercer dispositivo simbólico que articula ambas áreas, generándose así un nuevo espacio deproducción de sentido en lo estético.

D e este modo, espacio alternativo emergente, construcción estética de la homogeneidad, tensión regional-cosmopolita, constituyen núcleos de productividad simbólica que articulan la producción en ambos bloques, incorporando tensiones propias de nuestra cultura en su condicionamiento periférico. Su funcionamiento organiza sus mecanismos y sus operaciones generan espacios de especificidad estética. Es lo que otorga un sentido de "unidad" a la relación entre los espacios culturales hispano y lusitano, unidad que es en realidad articulación, paralelismo, convergencia. Pero es también el marco en donde se ponen en evidencia las divergencias y las disparidades.

$\mathrm{H}$ oy, en los inicios del siglo XXI, la introducción histórica de la escena mediática ha dado paso a nuevas formas de relación entre los individuos, diferentes maneras de interacción social, modos heterogéneos de "estar juntos". LoS medios se unieron a la escuela en el moldeamiento de los nuevos ciudadanos y tal vez en al gún momento parecerá obsoleto el estudio derelaciones entre culturas nacionales si no fuese porque el modo de integración al conjunto estará determinado por los modos históricos de construcción cultural. 
En la cultura de masas, propia de este momento, y en sus artefactos culturales, comenzó tem pranamente a producirse una vinculación entreel mundo hispanoamericano y el Brasil. Se hizo a través de la emergencia reformulada de un género que tenía expresión fuertemente latinoamericana: la telenovela. Este gé nero, que se produce primeramente para los mercados nacionales, generará un movimiento de vinculación interna del Brasil con América hispánica, a través de las exportaciones del producto ( $M$ ato, 2000). La Argentina, Colombia, Venezuela, pero sobre todo Brasil y M éxico a través de Televisa y TVG Iobo, serán sus grandes difusoras. Las exportaciones de los productos televisivos de las grandes corporaciones transnacionales (Warner Bros, Paramount, etc.) están apenas por encima de TVG lobo y Televisa. Pero esta vinculación ha tenido una sola dirección: ha dado a conocer al Brasil en la América hispana, a veces con un interesante trabajo histórico, pero no ha entrado la producción hispanoamericana en el monopólico mercado brasileño. Toda esta situación abrenuevoscampos de investigación.

La perspectiva que hemos tomado para esta observación es, pues, la de una relación estructural. Esta es una delas formas deaproximación a nuestras vinculaciones interculturales. Existen otros tipos de relación en una primera mirada: está el de las históricas concretas. Se trata de viajeros, publicaciones, relaciones intelectuales. H emos hecho críticas a esta perspectiva por el orden positivista en el que se ha insertado la comparatística en general, así como por la propensión a un monografismo exclusivo queno ha permitido entrever perspectivas de conjunto. En el caso nuestro ésta sería la dirección a tomar.

La situación es que hay importantes intelectuales que han desarrollado su actividad en "la otra parte" de América Latina. El estudio de sus vinculaciones puede seguramente poner de relieve campos y desarrollos no evidenciados. Es el caso por ejemplo de todo un grupo de intelectuales brasileños que vinieron a A mérica hispana en durante los años 60, en calidad de exiliados: C el so Furtado, Theotonio dos Santos, Vania Vambirra, Fernando EnriqueC ardoso, entre otros. Ellos trabajaron en la elaboración de la ciencia social latinoamericana que surgió en esos años como una mirada desde el sur a las relaciones socio-políticas y económicas internacionales. Funcionaron en torno a universidades y organismos internacionales, tales como Escolatina y CEPAL, y su trabajo intelectual fue un aporte con propuestas propias, que luego pudieron transformarse, pero que modificaron las maneras de ver y los métodos en el estudio del continente.

En la dirección contraria intel ectual es hispanoamericanos desarrollaron parte de su tarea en Brasil, viviendo allí por algún tiempo, o bien estuvieron en relación con la producción cultural de ese país. U no de los casos, queha comenzado a estudiarse, es el de la permanencia de Alfonso Reyes en Río de Janeiro, 
durante los años treinta, como diplomático. Allí dirigió, entre 1930 y 1934 el Correo Literario de Alfonso Reyes, que publicó en español. D esde luego que tuvo vinculaciones con los intelectuales de un momento histórico de gran efervescencia intelectual en ese país. Su relación con Ribeiro Couto, más tarde vinculado en amistad a G abriela M istral, da origen justamente a una carta en donde surge la idea desarrollada por Sergio Buarque de H olanda del "hombre cordial", uno de los primeros y grandes intentos en este siglo de llevar a cabo una re flexión sobre problemas identitarios del país, en el texto clásico Raízes do Brasil, de 1936.

O tro pensador que vivió en Brasil parte de su existencia, sobre todo en la juventud, fue el crítico uruguayo Emir Rodríguez M onegal. Señera en los años sesenta es su polémica relación con Angel Rama en torno a sus concepciones sobre la literatura latinoamericana, que se incorporan a opuestas perspectivas políticas, ambos participando primero en la revista $M$ archa y luego M onegal en $\mathrm{M}$ undo $\mathrm{N}$ uevo. Ambos se ocuparon en su trabajo de integrar las dos realidades que, para un ciudadano uruguayo, son tan próximas en la medida en que habita prácticamente un lugar de cultura de frontera en donde hay ligazones históricas profundas. Angel Rama no vivió en el Brasil, pero se interesó por la cultura de ese país y la integró pioneramente en sus investigaciones. Las relaciones del pensamiento de Rama con el fundamental de Antonio $C$ ándido empiezan hoy a estudiarse.

Como tercera perspectiva de observación, me parece que habría que pensar en los ejes externos. Estos ejes están situados en general en el ámbito metropolitano. París, por ejemplo, es un eje de articulación, como lo es Europa en general, en el momento de las vanguardias históricas: allí están tanto Borges y $\mathrm{H}$ uidobro como 0 swald de Andrade y Tarsila do Amaral. El eje está constituido otras veces por discursos articuladores, como el de G óngora, en el período colonial que impulsa dos discursos cercanos en varios aspectos, los de Sor Juana I nés de la $\mathrm{Cruz}$ y de $\mathrm{G}$ regorio de $\mathrm{M}$ atos. $\mathrm{O}$ tro caso es la centralidad de Nueva York, en los años sesenta de nuestro siglo, como un centro irradiador de cultura del que el segundo desarrollo vanguardista latinoamericano se apropia. En las relaciones que estamos estudiando es necesario pensar en un movimiento triangular en que uno delos vértices está situado en general en los países centrales, en la medida en que el desarrollo del discurso se enmarca en ellos; sea por razones políticas; sea por la readecuación del polo de referencia desde el momento de las repúblicas; sea por otras razones que determinan el impacto de un centro que irradia "subsidios cultural es" o que es buscado como tal.

0 tros centros articuladores nos permiten plantearnos ciertas preguntas. Es el caso de las culturas orientales (M aciel Borges, 2000). Por ejemplo, la presen- 
cia de Tagore en un momento determinado, o la presencia de esta cultura a través de géneros, como el haikai. Casos como Tablada en $M$ éxico y 0 swald de Andrade en Brasil que, no teniendo relación evidente con este referente, sin embargo lo incorporan. El interés por el 0 riente pasa además por la poesía anglo-sajona: Eliott y Pound. Así, la literatura latinoamericana tiene grandes "orientalistas", como Borges, Paz, H aroldo de Campos o Lezama Lima. H abría que observar también la presencia de esta cultura en el Brasil durante el siglo $X I X$, en donde Río era centro y sede del imperio que se extendía hasta el 0 riente. Por otra parte, la presencia japonesa actual en la cultura brasileña como en la Argentina y otras. H oy será necesario investigar el impacto de la inmigración coreana en vastos sectores de la región. El tema de la apropiación de 0 riente en nuestras culturas, los trayectos, las transformaciones, los circuitos comienza a constituir un significativo espacio de investigación.

Estas perspectivas de mirar, que no pretenden ser exhaustivas sino ordenadoras, nos abren una plural idad de espacios de contacto, es decir áreas de convergencia o divergencia, zonas de conocimiento en donde se observa el funcionamiento de las relaciones que hemos venido describiendo. Estos espacios de contacto se expresan en temasy problemas concretos. En esteorden dereflexión podemos apuntar por lo menos a cuatro.

En primer término, el de las delimitaciones, que tiene que ver con la evolución y relación de conceptualizaciones en ambos ámbitos, discusiones y eventualmente polémicas, hitos del pensamiento que han hecho una historia y han configurado parámetros conceptuales. Es el caso detemas y problemas como el de la noción deAmérica Latina, el dela idea deuna lengua propia, el dela discusión sobre el indígena, entre otros.

0 tro espacio se da en torno a los viajes. La mirada externa del viajero entrega la dimensión de la otra mirada. $\mathrm{H}$ ay viajeros que vienen desde Europa y entre gan la mirada sobre ambos bloques culturales- $\mathrm{H}$ umboldt, Rugendas-; hay viajeros internos que descubren la cercanía de los lenguajes y las culturas -J oaquín Edwards Bello, G abriela M istral-. H ay la mirada extranjera como subterfugio para mirar de modo diferente y autorizar la crítica de lo propio: un texto del siglo XVIII en Brasil tipifica esta perspectiva: Las Cartas chilenas, en M inas Gerais, de Tomás Antonio Gonzaga. Aquí setrata de la otredad como subterfugio. No hay efectivamente ninguna referencia histórica concreta a $\mathrm{C}$ hile. Como en $M$ ontesquieu, el autor recurrió a un lugar cuya imagen aparece en el marco de la lejanía y el exotismo, pero en el del interés por el mundo hispano en la metrópoli de la época. Las Cartas chilenas ponen en evidencia el distanciamiento que en el siglo XVIII existe entreel Brasil y sus vecinos hispanohablantes y, al mismo tiempo, el que los nexos se dan sobre todo a partir de una común rela- 
ción con la metrópoli peninsular. Todo parece quedar en las reglas de los comportamientos metrópoli-colonia del período: los vínculos son verticales, directos con ella, las relaciones horizontales son prácticamente inexistentes.

Un tercer espacio de contacto entre ambos bloques es el de fronteras. Existe una cultura de fronteras que es específica. La frontera, sea geográfica o cultural, diseña un espacio de convergencia y una dinámica intercultural. En la frontera se genera un espacio de entrelugar, donde la negociación moviliza niveles desiguales de aceptaciones, rechazos, transformaciones. Existe una zona de entre culturas en la incorporación de la tradición a la modernización violenta. El caso de las culturas indígenas de los distintos países de la cuenca amazónica con el español, portugués e inglés, por ejemplo, así como con la llegada delas misiones norteamericanas, la imposición de las hidroeléctricas o los enclaves empresariales nacionales e internacionales. El de las culturas de inmigración, por una parte internamente dentro de América Latina - migración económica o exilio político- así como con las oleadas migratorias de comienzos de siglo en el sur de Brasil -alemanes, italianos-, en la región de Buenos Aires, en el sur deChile, en Bolivia - españoles, alemanes y otros. Actualmente, como señalábamos, se está dando la situación de la relación con las culturas asiáticas, tanto en el Caribe, en donde esta inmigración es temprana, como en el resto del continente. En el Brasil ya comienzan a emerger textualidades, en el C aribe han surgido discursos literarios degran elaboración, como el de $\mathrm{N}$ aipaul. Un tema de cultura de fronteras muy claro es la configuración de un área compartida entreBrasil, U ruguay y el norte argentino, en donde hay una común expresión a veces con signo político diferente y en ambas lenguas, la de la gauchesca.

Para terminar, quisiera referirme a dos situaciones.

$\mathrm{H}$ ay un caso individual en quela falta de estudio sobre ambos bloques culturales del continente impide una comprensión cabal del discurso, en la medida en que se han solapado las relaciones textuales con una parte de los fundamentos biográficos. Es el caso de G abriela M istral. H emos estudiado esta situación en un volumen que debe ser publicado pronto y en un filme documental que tenemos previsto.

Al situar a la intelectual chilena en el mundo histórico, cultural y en concre to en el delos escritores deese país, percibimos con claridad una escritura y una personalidad que, contrariamente al sentido monolítico, como ha anotado Grínor Rojo, queda en evidenciauna subjetividad desgarrada, tensionada, de inflexiones plurales y contradictorias. H emos pensado entonces, y estamos trabajando en esa dirección, que Gabriela M istral, la construcción de la figura pública, es el gran proyecto de la campesina de Elqui Lucila Godoy. Se trata de la constitución, contra todos los obstáculos de género, clase, etnia y marginalización en un país centralista, de la voz pública, poderosa einternacional que llegó a ser. Este 
proyecto, el proyecto de Lucila, significó un costo enorme para Gabriela. La figura, en la que se proyectó siempre un tono demelodrama, tuvo en realidad el desgarramiento del drama, que se expresa en el discurso de una identidad escindida, contradictoria, fuertemente egocéntrica, percibiéndose, al lado deun discurso público degran auditorio, dificultades de interlocución en lo personal. En el período brasileño esto queda mayormente en evidencia. El lapso prolongado que ella vive en el Brasil, entre 1940 y 1945, es, históricamente, un espacio de encrucijada entre el espíritu libertario y profundamente creativo del modernismo y el universo represivo de corte fascistoide del gobierno de Vargas. En lo personal, entre algunos elementos que es posible observar allí están, por una parte, su vinculación con intel ectual es relacionados con distintos aspectos de la renovación modernista, como Cecilia M eireles, $H$ enriqueta Lisboa, M ario de Andrade, D rummond de Andrade, $M$ anuel Bandeira, $M$ urilo $M$ endes, entre tantos otros. Pero la experiencia del modernismo permea a la sociedad brasileña y a sus intelectuales, así como al momento y el medio en que vive $G$ abriela. Es allí en donde ella manifiesta su comprensión de las vanguardias - hay una carta a Povina Cavalcanti ${ }^{2}$ que lo pone en evidencia. Su escritura entonces toma el tono definitivo de la segunda edición de L agar y de Lagar II, el texto póstumo.

Por otra parte, el discurso de la maternidad y la infancia encuentra una contrapartida y se tensiona en textos relativos a la relación con el hijo, que ella dice "sobrino". Juan M anuel Godoy se suicida en Petrópolis el año 1943 y la correspondencia en torno al hecho da cuenta de la gran incapacidad de $G$ abriela para establecer diálogo con el adolescente, a partir de la construcción de un ego con tendencia a la victimización y fuertemente bloqueado a la posibilidad de ver los problemas del otro. Q ueda en esta etapa en evidencia una cierta megalomanía respecto a las relaciones personales, que toca también a su amistad con Stefan Zweig.

Además deesto están los mecanismos del universo erótico y afectivo. En este período puedeobservarse, también, quemás al lá de orientaciones detipo lésbico y heterosexual que puedan ser leídas en los textos tal como lo ha hecho alguna crítica, hay una importante fuerza autorrepresiva de lo erótico que tiene que ver con un trascendentalismo religioso por momentos integrista, todo lo cual se articula sin embargo con la vertiente popular heterodoxa que ha sido estudiada por Grínor Rojo.

Finalmente, en su dislocada territorialización respecto de Chile, su intención de permanecer de por vida en el Brasil, que forma parte de su ubicuidad territorial, ayuda a delinear, contrariamente a la victimización, los contenidos

${ }^{2}$ Archivo M useo Casa de Rui Barbosa, Río de Janeiro, Brasil. 
positivos de ese "país sin nombre" en donde dice morirá, que no es sino el entrelugar de la inmigración, al que ya nos hemos referido.

Como tratamos de mostrar en la publicación más extensa, el desconocimiento de la etapa brasileña oscurece formas importantes de comprensión del discurso de M istral.

En segundo lugar, las formas culturales de relación entre $\mathrm{H}$ ispanoamérica y Brasil quedan en evidencia cuando nos aproximamos a esa área cultural prácticamente desconocida que es la Amazonía. Allí confluyen ocho estados soberanos más la G uyana Francesa y las formas culturales comunes tienen que ver con la vida de sus poblaciones - veintitrés millones de personas- en uno de los territorios más vastos del continente que tiene como eje el mundo de las aguas situado en torno al río Amazonas y sus afluentes. Estos bajan desde los territorios andinos con las denominaciones de $\mathrm{N}$ apo, Putumayo, U rubamba, $\mathrm{M}$ adre de Dios y confluyendo con el M amoré, desde el sur, el Río N egro desde el norte, van a desembocar en el Solimoes, que luego toma el nombre de Amazonas. Se trata de una hoya hidrográfica enorme que ha generado históricamente formas de relación del hombre con la vida otras.

Esto significa también formas diferentes de producción en los imaginarios sociales. Allí el tiempo individual y social está regulado por el tiempo de las aguas, los ciclos del río, el período de la caza, la recolección, la pesca, la horticultura. Allí la subida y el descenso de las aguas regula los hábitos alimenticios, la dislocación familiar, la organización del trabajo (Acevedo y Castro, 1998). Se trata deun mundo fundamentalmente hispano y lusitano asentados en la historia común del viaje de Francisco de 0 rellana, que impulsa el imaginario febril de G onzalo Pizarro en la búsqueda del País de la $C$ anela. $D$ el relato de $G$ aspar de Carvajal. D ela aventura de Pedro de U rzúa y Lope de Aguirre en 1560, que nutre los relatos de Pedro Simón. La de tantos viajeros ebrios de imaginería de EI D orado, de amazonas, de iwaipanomas, de hombres con los pies al revés, de cinocéfalos, de fuentes de la eterna juventud, de zoología fantástica que dejaron en relatos, en grabados, en crónicas y relaciones.

Se trata deun mundo hispano y lusitano - también en partefrancés, inglés y holandés- que recibió la segunda gran entrada de la modernización con los viajeros científicos: La Condamine, H umboldt, entre tantos. Con ellos la apetencia europea y luego, desde fines del XIX, norteamericana encontraron un terreno propicio a la imaginería del enriquecimiento. La era del caucho marcó el desarrollo de por lo menos dos grandes ciudades: M anaos, "el París de los trópicos", y Belém la bella, con diseños del boloñés Landi, B elém do Gran Pará como diceel título de la novela de $D$ al cidio Jurandir. La novela había nacido en la zona en el siglo XVIII, en Surinam, y había tenido su gran éxito con el texto 
del escocés J ohn Gabriel Stedman, Joana or the Female Slave La imaginería del caucho levantó ciudades, generó una vida como caricatura del modelo europeo, levantó imperios y familias. También los hizo caer como a Fordlandia y en desbandada como en el momento supremo de la decadencia. D e allí surgieron textos como los de Euclides da Cunha, José Eustasio Rivera, se hizo el cine pionero de Silvino Santos. D ocumentos de la devastación y el horror. Porque los "coroneles de barranco" estaban mirando a Londres para vender el caucho, y aParís como modelo cultural mientras en el interior dela selva, en los seringales, imponían la explotación, la esclavitud y la tortura.

La historia y el destino de la panamazonia parecer tener el signo de la disyunción: la belleza y el horror, la riqueza y la pobreza extrema. La modernización de los militares, en los años sesenta del siglo XX, la occidentalización de la zona, con la Transamazónica, la incorporación de las grandes empresas mineras, hidroeléctricas, madereras, la ganadería, no han sido para los habitantes del área sino la continuidad de una racionalidad extraña y brutal, que, como el discurso ecológico fundamentalista, no les sirvea quienes necesitan vivir en un medio en donde han sabido históricamente establecer una relación equilibrada con la naturaleza, con-vivir con ella, sin inhibir la reproducción de las especies necesarias.

La configuración de esta área en la perspectiva de los estudios de la cultura, que conocemos tan poco, nos da cuenta no sólo de la bi-culturalidad. Aunque se trata de lenguas y culturas fundamental mente española y portuguesa, la variedad es tan grande que no es posible pensar sólo en el ámbito de lo indígena con que se identifica normalmente a la Amazonia. Su universo cultural es de múltiples orígenes: ingleses, holandeses, franceses, judíos, árabes actuando sobre poblaciones de diferentes etnias indígenas y de origen africano provenientes deantiguos esclavos o quilombolas; el mundo plural de seringueiros venidos de las mezclas étnicas del nordeste brasileño, como garimpeiros, de orígenes inusitados, ribeirinhos de difícil definición además de las poblaciones de origen 0 mezcla andina del Ilamado "pie de monte", en la Amazonia andina. En esta multiplicidad y efervescencia étnica los imaginarios también encuentran una dinámica febril. En ella conceptos como los de transculturación que proviene de la vivencia de dos culturas en mezcla - tanto en el caso de Fernando 0 rtiz como en el caso de su reconsideración por Rama- se nos hacen mínimos. Parecen constituir procélulas de un proceso mucho más complejo, que además está entrando en un vertiginosa modernización impuesta. Aquí la hibridación aparece como un mecanismo simplificador. D e trata más bien de una negociación pluricultural, negociación que ha entrado en grados mayores o menores en procesos de hibridación, en diferentes tiempos, alternancias, formas. 
Con las dos situaciones propuestas, tal vez quede más evidente la necesidad de entender la articulación de nuestras culturas. En lo individual y en lo social. Producir conocimiento es una forma de apropiarlas, de develar su complejidad, de iluminar los vacíos, y como en la Amazonia, para América Latina, de reivindicar su pertenencia. En este último caso, ello aparece cada día más como una necesidad imperiosa.

\section{REFERENCIAS}

Acevedo, Rosa y Etna C astro. 1998. N egros do Trombetas. Guardiaes de M atas e Rios (2ª ed.). Belém do Pará: Editora C ejup.

M aciel Borges, Esther. 2000. "Pontos de confluencia: América Latina em diálogo com 0 O riente - conversa con H aroldo de Campos". En Brandao Santos, Luis Alberto e Pereira, M aría Antonieta, Trocas culturais na América Latina. Belo H orizonte: Pós-Lit / Fale / U fm G; N elam / Fale / U fm G.

$M$ ato, $D$ aniel. 2000. "Telenovelas: transnacionalización de la industria y transformaciones del género". En García Canclini, N éstor et al. Lasindustrias culturales en América Latina. Buenos Aires: Eudeba.

Schwartz, Jorge. 1993. "Abajo Tordesillas", revista Casa de las Américas. 